\title{
Tracing Knowledge Flow as Strategy towards Measuring Corporate Knowledge
}

\author{
https://doi.org/10.3991/ijac.v10i1.6364 \\ S.M.F.D Syed Mustapha \\ Taif University, Taif, Saudi Arabia \\ smfdsm@gmail.com; syed.malek@tu.edu.sa
}

\begin{abstract}
Corporate knowledge is essential mainly to knowledge-intensive organizations. Its success is always associated with the performance of the organization through ROI (Return of Investment). While the scope of corporate knowledge is wide, we redefine in the context of computational environment and demonstrate how corporate knowledge can be modelled and subsequently enabled it to be measured. With this new ability, the knowledge flow within the learning activities can be traced and the individual performance can be measured based on the learning goal being set.
\end{abstract}

Keywords-knowledge management, knowledge transfer educational technology, learning technology

\section{$1 \quad$ Introduction}

Management of corporate knowledge is essential to maintain organizational performances; it allows continuous regeneration of knowledge and innovation through effective knowledge sharing, retention of corporate skills and knowledge as well as efficiencies in making corporate decision.

Our literature indicates that corporate knowledge has no concrete definition even though it has been used widely and its meaning has been elaborated in the context of the author who used the term. For example, Pierre et al stated that corporate knowledge requires one to have information that is accessible throughout the organization as well as an information technology framework to support them [1]. Yang et al argued that corporate knowledge is managed by agents who were acting on managing the knowledge in a dynamic and uncertain environment and at the same time cooperating each other in achieving corporate goal [2]. Gregoris et al [3] describes corporate knowledge as having knowledge artefacts to be managed by computer-based corporate memory and at the same time having appropriate methodologies and tools as processes in managing the knowledge. Some may refer corporate knowledge as interchangeable term with corporate knowledge as knowledge which is characteristically explicit. For example, Van et al [4] defined it to be an explicit, not embedded within the organization and continuously to be presentable in the form of information or knowledge within and organization; while Nagendra et al [5] defined knowledge as 
tangible things like company products, clientele profile, marketing and financial reports and business goals.

Having said about how organizations conceptualize the corporate knowledge, it can be assumed that management of corporate knowledge is essential and understanding the principles to ensure addressing the success factor is taken place. The essential factors for having a successful Knowledge Management or Knowledge Management System (thereafter, KM/KMS respectively) have been discussed in many literatures. It is commonly agreed that the essentials factors should not be addressed in silo manner as it requires a holistic approach and integration among the $\mathrm{KM} / \mathrm{KMS}$ components [6]. Nevertheless, this paper focusses on one aspect in KMS which is the learning aspect within the organization.

Learning in organization has been mentioned in the literature as a significant process in the entire architecture of the KM/KMS. In a corporate environment, measuring the learning among the corporate members and its affiliations can be a daunting task as it involves internal and external parties such as managers, customers, suppliers, management, shareholders and others. Usually, the learning is assumed to take place based on the ROI performance [12]. In other words, the members of certain departmental unit who have gone through certain training period and demonstrate an increase of productivity or decrease in cost indicates a return on ROI [7]. Whether this is commonly accepted view, a survey which is done by Mumma et al [8] indicated that only $12 \%$ of the surveyed companies observed that the learning process through training had strong alignment with the business strategies. Most companies fail to demonstrate direct benefit from the staff training since they do not have an integrated and comprehensive learning or training plan. Hence, the learning and ROI seemed to show low correlation to some of these corporations. To overcome these issues, Deking [9] as cited in [10], formulated a framework for measuring the knowledge and knowledge management in terms of the value and status using several types of instruments such as balance scorecard, knowledge portfolio, cost saving analysis, scoring models and cross organizational benchmarking. Bersin [11] established a practical model for measuring performance based on corporate training for individual in four phases which include problem definition, training solution, individual performance and organizational performance.

Based on the literature above, there is a gap in between the learning plan, learning process and measuring the competency attributes of the learner. In some corporations, a clear mapping between the training program or organization learning with the expected learning outcomes or the training effectiveness are not known. The simple reason is that the effectiveness of the training and learning processes in meeting the business goals are taken as the result of collective effort of every member in the organization. In our paper, we describe the concept of tracing knowledge flow in monitoring the corporate learning environment for every individual and how learning is measured. In the next section, we discuss the type of corporate knowledge that is applicable in our context followed by another section that explained the learning process based on the corporate knowledge that can be measured and traced. 


\section{Corporate Knowledge}

The focus on corporate knowledge for this work is on codifiable corporate knowledge in computational form. Codifiable knowledge is referred to explicit knowledge that may derive from articulated tacit knowledge or structured or unstructured knowledge that are presentable in explicit form and in digital media [13]. Corporate knowledge differs by the sectors such that knowledge-intensive organizations may be require dynamical change in knowledge generation, more volatile and innovative compared to production-based or regulated-based organizations where knowledge is embedded in its standard operating procedure and changes are less affected with business trends. Industries such as consultancy, finance, advertisement, banking, education, healthcare are the targeted sectors for this research.

Organizational structure is not the primary issue as the principles in managing corporate knowledge should be applicable in all organization embracing the same knowledge management system and practices [mentioned in [14,15] for guiding principles in KM. We believe with the advent of information and communication technologies; geographical distance is not an obstacle to maintain efficacy in the communication flow. In our proposed corporate structure, the information and communication takes place mainly in ICT platform such that data, information and knowledge can be retained in computational form. Hence, multinational corporations (MNCs) or transnational corporations(TNCs) or single-location operated corporation shall be able to adopt the same principles in KM.

Corporate knowledge can be categorized into format which are structured documentations that are stored in corporate database and DMS (Document Management System) and unstructured where knowledge is sparsed and uncategorized. The unstructured corporate knowledge (UCK) is the interest in our work as it allows sharing of knowledge on multiple views, regeneration of ideas, sharing of experiences and identification of knowledge expert. Hence, the ICT platform is an open platform that allows corporate members to post opinions and share relevant materials in various forms.

\section{$3 \quad$ Learning Organization}

According to Argote [16], learning organization takes place in three sub-processes: creating, retaining and transferring of knowledge. Learning product could be in the form of new knowledge artifact such as new architectural design, product design, marketing brochure; another type of learning product is in the form of opinion, argument, debate, analysis and others that co-occur during the development of knowledge artifact. The latter is more significant as the thinking process and discussion thread can be recorded and captured for future review and consideration, in order to avoid repetition in similar decision making process. Another aspect of learning which is important in the organization is the individual's learning lifecycle since every individual contributes towards achieving the overall business objectives. Every individual is set with the learning goals, learning process and finally the learning outcome. 
Learning goal consists of targeted knowledge domain, learning activities, learner's participation network and learner's profile. Learning process defines the phases of learning that a learner must go through to determine the level of mastery s/he has attained, the number of knowledge domain to be assigned and building of expertise. Learning outcome is associated with the learning goals in which it is measured numerically. In the next subsections, we describe the learning artifacts, corporate learning and learning strategy.

\subsection{Learning Artifacts}

Learning artifacts is defined as object that has characteristics of being "durable, made public, long lasting and materially presented" [17]. It is a concept adopted by educational psychologist for students to demonstrate their understanding in the classroom with artifacts such as paintings, drawing, sculptures and these are not perishable. In the context of corporate knowledge, learning artifacts are the products that are developed as a result of social or business communications in the formal and informal settings such as meetings, serendipitous drop-in, chats, online discussion, asynchronous communication, meeting minutes, contract agreement and also individual learning such as visiting web page, downloaded internet resources and multimedia objects (images, video, audio etc.). In a computational environment, these learning artifacts are available and traceable.

\subsection{Corporate Learning}

Corporate learning is performed in two environments - Traditional Learning (TL) and Online Learning (OL). TL is an environment where learning takes place in noncomputational form and not discernible in digital format, for examples, attending seminar, ICT skill-based training or other professional courses. We argue that it is possible to transfer knowledge based on these types of training into a repository of corporate knowledge using the current information technology [18]. Sharing of training modules, PowerPoint slides and personal notes that are associated with the trainings are ways to reposit learning artifacts for the use of other members. OL has been widely accepted in many corporations as alternative to TL and it is done in-house. OL can be conducted on web-based or client-server based or standalone machine. There are various e-learning packages that are pedagogically organized which includes assessment and the content is tailored uniquely for the corporate use. OL also supports social communications such as online chatting, forum discussion, blogging, Wikipedia development, resource creation and sharing. In an integrated environment where these features are available, learner has the opportunity to use various platforms to demonstrate one's learning. 


\subsection{Learning Strategy}

Individual learning is the focus in this research work albeit the entire learning strategy is a composition of all individual towards achieving the corporate's business goal. The followings are the five factors needed in setting the learning strategy:

1. Knowledge domain (KD) identification - KD can be a specialized or general subject matter that the learner needs to comprehend. KD can be built using ontology automatically or semi-automatically from the textual document $[19,20,21]$. The collection of relevant texts emphasizing certain key concepts can be used as the basis to build $\mathrm{KD}$. A learner can be assigned to one or more KDs depending on the training needs.

2. Learning Phases $(\mathrm{LPh})$ - an individual deal with two types of knowledge; tacit and explicit knowledge. The knowledge is transformed from one another depending on the activities. For example, reading transform the explicit knowledge from the reading text into tacit knowledge. The learner processed his/her understanding with cognitive pre-processing and possibly regenerate new understanding or conflicting argument. This process happened between implicit and implicit knowledge. New ideas or arguments are externalized in various forms such as oral presentations, video recording, blogs and other form of explicit materials.

3. Learning Profile (LPr) - some levels of recognition are labelled to each learner based on his/her learning profile. Learning profile is built based on one's commitment and activities during the Learning Phases. For example, one who is an active participation in a discussion and being dominant in a discussion on a specific domain, will earn higher recognition in his profile.

4. Social Status (SSt) - some levels of recognition and identity established among the corporate members as a result of one's leadership, dominance behavior, influences and communication effectiveness. In a computation form, these can be captured and can be calculated based on the frequency of interactions and number of reference made by others to him/her as point of reference. The influences can be observed from the responses and replies that indicate support to one's idea and these can be computed.

5. Measurement - data are captured for every actions made by the learners, hence, these data can be computed and measured to be translated to a more meaningful results. Measurement requires computation on the gap between the learning goals and learning outcomes. Learning goal consists of the targeted $\mathrm{KD}, \mathrm{LPh}, \mathrm{LPr}$ and SSt which can be set for every individual or standard goal set at corporation level for everyone.

In the following section, we demonstrate the application of the knowledge transfer and knowledge trace for measuring corporate performance. 


\section{Measuring Corporate Knowledge}

In the proposed application of building a corporate knowledge, the followings are the items that comprise a corporate knowledge unit (CKU):

1. Knowledge Object (KO) - personal's opinions, explanations, arguments, recommendations, suggestions that are possibly presented with other sources such as design, PowerPoint slides, statistical figures, factual information and others;

2. Multimedia (MM) - using video clips, audio, animation, guidelines, reports, text, web page, physical objects that are presentable in multimedia format;

3. Semantic Tagging of Knowledge Object (STKO) - the semantic content is described in text format in order to allow text processor to extract keywords describing the essence of the knowledge object.

The CKU is initiated at every action performed by the corporate learner in the learning phases $(\mathrm{LPh})$. For example, learner A posted his opinion with an attached resource, CKU will be formed as integrated unit shown in Fig. 1.

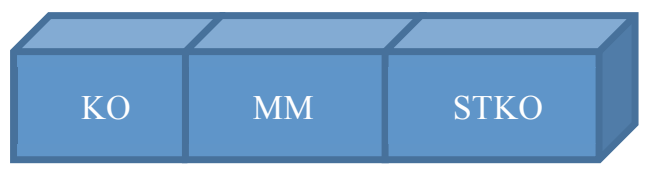

Fig. 1. Schematic diagram of CKU

Each CKU is characterized into measurable unit based on the' quantity and quality of the content. For example, in $\mathrm{KO}$, the length of the text gives the quantity value while the relevancy to the context is the quality value. Context refers to the content of the current discussion or content. For STKO, the semantic tag has details on content which is labelled with named-entity attributes such as location, organization, quantity, time etc.; and these details are used for retrieval and matching purpose. MM is an additional resource that is used to enhance the content of the knowledge that is described in text form as in STKO by using video, audio and others. In the following subsections, we illustrate further on the use of CKU for tracing knowledge.

\subsection{Tracing Knowledge Flow}

CKU is owned by every learner who initiated learning actions such as posting argument, uploading video, creating blogs. As CKU has the content (in KO) and semantic descriptors (in STKO), the flow of CKU within among the members can be traced.

In our work for tracing knowledge, the focus is on Learning Phases $(\mathrm{LPh})$ as one of the learning strategy. With CKO, the tracing for knowledge transformation such as "tacit-to-explicit (TE)", "explicit-to-implicit (EI)" and "explicit-to-explicit (EE)" will be possible. The examples of learning actions that are characterized by different knowledge transformation is shown in Table 1. 
Table 1. Examples of Knowledge Transformation

\begin{tabular}{|c|l|}
\hline $\begin{array}{c}\text { Knowledge } \\
\text { Transformation }\end{array}$ & \multicolumn{1}{c|}{ Examples } \\
\hline TE & Posting personal notes, arguments, Creating Wikis, Blogs \\
\hline EI & Watching video clips, Listening to audio, Reading blogs \\
\hline EE & Classifying documents, cataloging resources \\
\hline
\end{tabular}

The examples for each knowledge transformation can be expanded further depending on the available technologies supporting them. The only limitation is the transformation between "tacit-to-tacit" which occur within internal oneself.

Once the activities are converted into CKO form, the flow can be traced. For example, Learner A has been tasked to learn on Topic A and the keywords for this topic is defined in KD identification (ref Learning Strategy). As he performed the activity, the keywords defined in KD is matched against KO and STKO to determine the relevancy. Since a learner is allowed to participate in various knowledge domain, the matching on keywords to determine the relevancy for each $\mathrm{CKO}$ he/she produced has to be done to ensure that he/she participated in the knowledge transformation processes for each knowledge domain set for him/her at the Learning Profile (LPr) and Social Status (SSt). Finally, the flow of the knowledge can be traced and the measurement is calculated based on the goal set at LPr and her/his final achievement. In a corporate environment, monitoring is a continuous process.

\section{Conclusion}

Corporate knowledge retention and reuse have gained interest mainly on how it influences the ROI performance. While many effort focus on the overall ROI as the yardstick to measure corporate learning, our focus is on individual learning. We describe how corporate knowledge can be modelled in computational format and processing them to trace its flow throughout the learning activities. The work is significant such that corporate knowledge can be measured and the flow can be traced.

\section{$7 \quad$ Acknowledgment}

I would like to thank Taif University for providing me the opportunity to conduct the research and facilitate with the resources.

\section{$8 \quad$ References}

[1] P. Maret, M. Hammond, and J. Calmet. Virtual Knowledge Communities for Corporate Knowledge Issues, 2004. 5th International Workshop on Engineering Societies in the Agents World (ESAW, Toulouse, France), Springer LNCS 3451, pp.3344.

[2] Y. Yang and J. Calmet. Ontobayes approach to corporate knowledge. In Foundations of Intelligent Systems, 274-283, Springer, 2006. https://doi.org/10.1007/11875604 31 
[3] G. D. Apostolou, R. Young and A. Abecker, (2001),"Knowledge networking: a holistic solution for leveraging corporate knowledge", Journal of Knowledge Management, Vol. 5 Iss 1 pp. $94-107$

[4] G. Eason, B. Noble, and I. N. Sneddon, "On certain integrals of Lipschitz-Hankel type involving products of Bessel functions," Phil. Trans. Roy. Soc. London, vol. A247, pp. 529551, April 1955. https://doi.org/10.1098/rsta.1955.0005

[5] J. Clerk Maxwell, A Treatise on Electricity and Magnetism, $3^{\text {rd }}$ ed., vol. 2. Oxford: Clarendon, 1892, pp.68-73.

[6] R. Maier and T. Hädrich, "Centralized versus peer-to-peer knowledge management systems," Knowledge and Process Management, vol. 13, pp. 47-61, 2006. https://doi.org/10.1002/kpm.244

[7] F. Hasanali. Critical Success Factor of Knowledge Management in Michael E.D. Koenig and T. Kanti Srikantaiah, edited in Knowledge Management Lessons Learned: What Work and What Doesn't. Asis Monograph Series, Information Today Inc (2004).

[8] S. Mumma, A. Todd, and E. Trolley. Running Training Like A Business:2011 Research Update, Corporate University Xchange (From: https://www.corpu.com/documents/ RTLAB ebook rev011311.pdf, Download: $31^{\text {st }}$ August 2016)

[9] I. Deking. (2002): Management des Intellectual Capital - Bildung einer strategiefokussierten Wissensorganisation, dissertation, Technical University of Munich

[10] U. Faisst, and F. Resatsch. (2004). Measuring the performance of knowledge management initiatives. Diskussionspapier WI-135, Universität Augsburg. Augsburg.

[11] J. Bersin. High-Impact Learning Measurement: Best Practices, Models, and BusinessDriven Solutions for the Measurement and Evaluation of Corporate Training, Bersin \& Associates / Josh Bersin, November 2006

[12] Henley Business School, Corporate Learning Priorities Survey 2015: Using Learning and Development To Achieve Strategic Business Aims, University of Reading (Available: http://www.henley.ac.uk/files/pdf/exec-ed/2015 Corporate Learning Survery.pdf Download: $31^{\text {st }}$ August 2016)

[13] A.D. Banasiewicz. What is knowledge. MGMT E-6750, Harvard Extension School, Harvard University, Spring 2013 (Available: http://isites.harvard.edu/fs/docs/icb.topic 1346261.files/Banasiewicz\%20Excerpt\%201.pdf Download $4^{\text {th }}$ September 2016)

[14] J. Magnusson., K. Valentin, and A. Nilsson. Knowledge Management Theory. In Interorganizational Settings. Organizational Knowledge and Learning Conference (Available: http://www.gu.se/english/research/publication?publicationId=70143 Download $4^{\text {th }}$ September 2016)

[15] T. Tobin. Ten Principles for Knowledge Management Success. (Available: http://hosteddocs.ittoolbox.com/Knova20606A.pdf Download $4^{\text {th }}$ September 2016)

[16] L. Argote. Organizational Learning Research: Past, Present and Future. Management Learning, 42(4), pp 439 - 446. https://doi.org/10.1177/1350507611408217

[17] Learning Artifact (Education).

[18] Available: https://en.wikipedia.org/wiki/Learning artifact (education)

[19] E. Innola, and A. Tuomisto. Knowledge Transfer and Initiation Process: About New Employee Becoming Old Reliable. In: The Fifth European Conference on Organizational Knowledge, Learning and Capabilities, 2004. (Available: http://www2.warwick.ac.uk/fac/ soc/wbs/conf/olkc/archive/oklc5/papers/i-4 innola.pdf Download: $5^{\text {th }}$ September 2016)

[20] J. I. Toledo-Alvarado, A. Guzmán-Arenas and G. L. Martínez-Luna. Automatic Building of an Ontology from a Corpus of Text Documents Using Data Mining Tools, Journal of Applied Research and Technology Vol. 10 No.3, June 2012, pp 398 - 404. 
[21] B. Mithun, S. and S. Munirathnam. Automatic Ontology Creation from Text for National Intelligence Priorities Framework (NIPF). (Available: http://ceur-ws.org/Vol-440/pap er2.pdf Download $6^{\text {th }}$ September 2016)

[22] S.M.F.D Syed Mustapha. KFTGA: A tool for tracing knowledge flow and knowledge growth in knowledge sharing environment. Information Knowledge Systems Management, vol. 11 , no. 3,4, pp. 205-224, 2012

\section{Author}

S.M.F.D Syed Mustapha is a professor in Computer Science Department, College of Computers and Information Technology, Taif University, Saudi Arabia. His main research interest is on building intelligent techniques through knowledge modelling for learning in which he had applied in various domains such as rheology, inorganic chemistry, social communication and community of practice. He received his $\mathrm{PhD}$ and MPhil from University of Wales, UK and Bachelor of Science (Computer Science) from University of Texas, USA. He has served in various positions in the university as head of department, deputy dean, dean of faculty in the previous employment in various institutions of the past 15 years. His last administrative position was as Vice President (International) and prior to that as the Vice President (Operations and Technology). He has published more than 80 papers at the international journals and conferences in which $70 \%$ of the papers as the first author or single author. He serves as board of reviewers in various scientific committee for international and local conferences and journals. He is a Fellow member of British Computer Society. He completed his postdoctoral programme under Hitachi Fellowship Foundation in University of Tokyo, Japan (smfdsm@gmail.com;syed.malek@tu.edu.sa).

Article submitted 22 October 2016. Published as resubmitted by the author 27 December 2016. 